PENGARUH PRONE POSITIONING TERHADAP RESPIRATORY RATE DAN SATURASI OKSIGEN PADA BAYI GAWAT NAPAS (RESPIRATORY DISTRESS SYNDROME) DI RUANG NICU RSUD GUNUNG JATI CIREBON

\author{
Titin supriatin ${ }^{1^{*}}$, Yani Nurhayani ${ }^{2}$ \\ ${ }^{1 *}$ Program Studi D III Keperawatan STIKes Ahmad Dahlan Cirebon \\ Email : titinsupriatin821@gmail.com \\ 2 Program Studi D III Keperawatan STIKes Ahmad Dahlan Cirebon \\ Email : yani.nurhayanii123@gmail.com
}

\begin{abstract}
THE EFFECT OF PRONE POSITIONING ON RESPIRATORY RATE AND OXYGEN SATURATION IN INFANTS WITH RESPIRATORY DISTRESS SYNDROME IN NEONATUS INTENSIVE CARE UNIT AT GUNUNG JATI HOSPITAL CIREBON.
\end{abstract}

Background : Respiratory Distress syndrome (RDS), also known as respiratory distress syndrome, is a major threat to infants and children who are recovering from a serious illness. Currently, RDS is the leading cause of newborn death. Management of RDS include improving oxygenation, prevention of infection, maintaining vascular pressure and cardiac output, adequate nutrition, positioning to improve functional residual capacity. The prone positioning for the baby is a energy saving position, because this position will reduce heat loss. This is because in the prone positioning, the baby's feet are flexed, thereby reducing the body's metabolism resulting in a decrease in the amount of heat loss. Another reason is that in the prone position the baby's face touches the blanket or bed so that the baby's face is not exposed to air and allows a decrease in heat loss through the radiation process.

Purpose : The purpose of this study was to determine the effect of the prone positioning on respiratory rate and oxygen saturation in respiratory distress syndrome (RDS) infants in NICU at Gunung Jati Hospital, Cirebon.

Methode : The methode of this research is a quasi-experimental study with a non-equivalent control group pre and post test design. This study used a random sampling technique to 38 respondents. The analysis in this study uses paired $t$ test analysis.

Result : The results showed that the prone positioning can support the improvement of respiratory rate and oxygen saturation in infants with RDS.

Conclusion : There are improvement of respiratory rate and oxygen saturation after prone positioning given.

Keywords : Prone, Respiratory distress syndrome, Respiratory rate, oxygen saturation. 


\section{INTISARI : PENGARUH PRONE POSITIONING TERHADAP RESPIRATORY RATE DAN SATURASI OKSIGEN PADA BAYI GAWAT NAPAS (RESPIRATORY DISTRESS SYNDROME ) DI RUANG NICU RSUD GUNUNG JATI CIREBON}

Latar belakang : Respiratory Distress syndrome (RDS) atau dikenal dengan sindrom gawat napas, merupakan ancaman utama pada bayi dan anak yang berada pada masa pemulihan dari penyakit berat. Saat ini RDS merupakan penyebab utama kematian bayi baru lahir. Penatalaksanaan RDS diantaranya adalah memperbaiki oksigenasi, pencegahan infeksi, mempertahankan tekanan vascular dan curah jantung, nutrisi yang adekuat, pemberian posisi untuk memperbaiki kapasitas residu fungsional. Posisi prone pada bayi merupakan posisi yang sangat menghemat energi, karena posisi ini akan menurunkan kehilangan panas. Hal ini disebabkan karena pada posisi prone, kaki bayi fleksi sehingga menurunkan metabolisme tubuh akibatnya terjadi penurunan jumlah kehilangan panas. Penyebab lain juga dikarenakan pada posisi prone wajah bayi menyentuh selimut atau tempat tidur sehingga wajah bayi tidak terpapar dengan udara dan memungkinkan terjadinya penurunan kehilangan panas melalui proses radiasi

Tujuan : penelitian ini adalah untuk megetahui pengaruh posisi prone terhadap respiratory rate dan saturasi oksigen pada bayi respiratory distress syndrome (RDS) di ruang NICU RSUD Gunung Jati Cirebon.

Metode Penulisan : Penelitian ini merupakan penelitian kuasi experimental dengan desain pre and post test non equivalent control group. Penelitian ini menggunakan tehnik random sampling terhadap 38 responden. Analisis dalam penelitian ini menggunakan analisis paired t test.

Hasil : Hasil penelitian menunjukkan bahwa posisi prone dapat mendukung perbaikan respiratory rate dan saturasi oksigen pada bayi dengan RDS.

Kesimpulan : terdapat peningkatan respiratory rate dan saturasi oksigen setelah dilakukan intervensi posisi prone.

Kata kunci : Prone, Respiratory distress syndrome, Respiratory rate, saturasi oksigen.

PENDAHULUAN
Sindrom gawat napas atau
yang lebih dikenal dengan
Respiratory Distress Syndrome
(RDS), adalah salah satu ancaman
penting pasien anak-anak dan bayi
baru lahir, terutama saat masa
penyembuhan setelah sakit keras.
Salah satu tanda gejalanya adalah
kurangnya oksigen dalam darah
dalam tiga hari (L Donna Wong et all,
2009). Salah satu Tindakan yang
dilakukan adalah dengan
memberikan bantuan oksigenasi,
mengantisipasi agar tidak terjadi
infeksi, serta upaya untuk

membertahankan tekanan vaskuler dan curah jantung, dan tak lupa juga pemenuhan kebutuhan nutria yang adekuat, pengaturan posisi yang tepat. Asuhan keperawatan pada RDS melibatkan pemantauan terhadap curah jantung, frekuensi jantung, perfusi, pengisian kapiler, dan haluaran urine, serta pengkajian status oksigenasi. Analisis gas darah dan oksimetri nadi merupakan alat evaluasi yang penting bagi kasus RDS ( $L$ Donna Wong et all, 2009).

Angka kejadian RDS di Eropa sebanyak 2-3\%, di Amerika sebanyak 1,72\%, di Asia Tenggara sekitar 5 - 
10\% RDS didapatkan pada bayi kurang bulan dan $50 \%$ pada bayi dengan berat badan 501-1500 gram. Saat ini RDS merupakan penyebab utama kematian bayi baru lahir, diperkirakan $30 \%$ dari semua kematian bayi disebabkan oleh RDS dan komplikasinya. $60-80 \%$ terjadi pada bayi yang umur kehamilannya kurang dari 28 minggu, 15-30\% pada bayi antara 32-36 minggu, dan $3 \%$ pada bayi yang lebih dari 37 minggu (World Health Organization, 2011)

Data menunjukkan bahwa penyebab kematian neonatal dini (06 hari) terbanyak adalah gangguan sistem pernafasan (Riset Kesehatan Dasar, 2007).

Hal tersebut didukung salah satu penelitian, yang menyatakan bahwa RDS merupakan penyebab utama terhadap angka kesakitan dan kematian pada bayi. Angka RDS pada bayi dan anak jauh lebih tinggi dibandingkan dewasa, kira-kira $2 / 3$ kasus gawat napas anak terjadi pada tahun pertama kehidupan (Anggrek, 2008).

Berdasarkan hasil study pendahuluan di NICU RSUD Gunung Jati Cirebon, 6 Maret 2019, jumlah kasus RDS cukup tinggi dan menempati peringkat 1 dari kasus lainnya di ruangan tersebut. Berdasarkan hasil rekapitulasi 3 bulan terakhir kasus RDS mencapai 156 kasus. Sedangkan jumlah kematian bayi RDS pada bulan Januari 2018 sebanyak 5 bayi, dan pada bulan Februari meningkat menjadi 6 bayi (RSUD Gunung Jati, 2019).

Penelitian serupa tentang posisi prone, diperoleh hasil bahwa pemberian posisi prone mendukung perbaikan status oksigenasi pada bayi yang mengalami masalah pernafasan, dibandingkan dengan posisi supinasi. Hasilnya terdapat perbandingan bermakna terhadap frekuensi nafas bayi sebelum dan sesudah posisi
(Kusumaningrum, 2010).

pronasi

\section{METODE}

Penelitian ini merupakan penelitian kuantitatif, jenis penelitian yang digunakan adalah penelitian analitik, menggunakan desain penelitian kuasi experimental yaitu dengan metode experiment, dengan rancangan pre tets - post test non equivalent control group design.

Populasi dalam penelitian ini adalah semua pasien dengan RDS yang dirawat di ruang NICU RSUD Gunung Jati Kota Cirebon, dengan tekhnik pengambilan sampel yaitu simple random sampling (acak sederhana).Jumlah sampel yang digunakan dalam penelitian ini sebanyak 38 bayi RDS yang di rawat di ruang NICU RSUD Gunung Jati Cirebon. Dilaksanakan dari April juli 2019. Penelitian dilakukan setelah mendapatkan izin penelitian dari Direktur RSUD Gunung Jati Kota Cirebon, dan peneliti melakukan penelitian dengan memegang prinsip-prinsip etik penelitian dan sikap ilmiah (scientific attitude).

Penelitian ini terdiri dari 2 kelompok yaitu kelompok intervensi dan kelompok kontrol. Pada kelompok intervensi maka di berikan intervensi berupa posisi prone disertai pengobatan standar yang diberikan oleh rumah sakit dan kelompok kontrol hanya diberikan pengobatan standar yang diberikan yang diberikan oleh rumah sakit.

Instrumen penelitian yang digunakan adalah lembar questioner yang berisi tentang karakteristik resposnden, serta alat ukur seperti : pulse oksimeter, jam tangan, yang sudah dikalibrasi, sehingga tidak perlu dilakukan uji validitas. Sedangkan dalam pengambilan data peneliti melibatkan asisten peneliti. Untuk mendapatkan data dan 
persepsi yang sama antara peneliti dan asisten peneliti maka dilakukan persamaan persepsi dan simulasi (uji asisten peneliti dengan acuan SOP yang telah dibuat).

Tahap pelaksanaan prscedural meliputi tahap : Pre Test yaitu pengukuran saturasi oksigen dengan alat pulse oksimeter dan respiratory rate dengan menggunakan jam tangan sebelum dilakukan posisi prone, selanjutnya perlakuan posisi prone terhadap subyek penelitian yang dilakuakn selama 20 menit, hal ini dilakukan tiap shift dan selama 3 hari, setelah itu dilakukan post test yaitu evaluasi

Tabel 1.1 pengukuran kembali saturasi oksigen dan respiratory rate.

\section{HASIL}

Analisis Univariat
Analisis tahap pertama pada
penelitian ini adalah analisa
univariat. Variabel-variabel yang
dilakukan analisa univariat adalah
respiratory rate dan saturasi oksigen
(pre dan post test).

\begin{tabular}{|c|c|}
\hline Variabel & Posisi prone \\
\hline $\begin{array}{ll}\text { Usia } & \text { gestasi } \\
\text { (minggu) } \\
\text { Mean } \\
\text { Median } \\
\text { SD Deviasi } \\
\text { Min-Max }\end{array}$ & $\begin{array}{c}34,63 \\
36 \\
2,99 \\
28-38\end{array}$ \\
\hline $\begin{array}{l}\text { HB } \\
\text { Mean } \\
\text { Median } \\
\text { SD Deviasi } \\
\text { Min-Max } \\
\end{array}$ & $\begin{array}{c}13,14 \\
13,2 \\
1,17 \\
10,40-15,50 \\
\end{array}$ \\
\hline $\begin{array}{l}\text { Suhu } \\
\text { Mean } \\
\text { Median } \\
\text { SD Deviasi } \\
\text { Min-Max }\end{array}$ & $\begin{array}{c}37,16 \\
37,2 \\
0,62 \\
36,10-39\end{array}$ \\
\hline
\end{tabular}

Berdasarkan tabel 1.1, diketahui bahwa karakteristik bayi dengan RDS di ruang NICU RSUD Gunung Jati Cirebon berdasarkan usia getasi (minggu) pada kelompok intervensi posisi prone rata-rata berusia 34,63 minggu, sedangkan pada kelompok intervensi posisi lateral berusia 34,52 minggu. Nilai $\mathrm{Hb}$ pada kelompok intervensi posisi prone rata-rata $13.14 \mathrm{mg} / \mathrm{dl}$.

\section{Analisa Bivariat}

Analisis bivariat adalah analisis untuk menguji hubungan yang signifikan antara dua variabel, atau untuk mengetahuai adakah perbedaan antara dua kelompok atau lebih (Sabri, 2011). Untuk menentukan jenis uji yang digunakan, terlebih dahulu dilakukan uji normalitas dengan shapiro wilk tes (sampel < 60). Analisis bivariat menggunakan uji T sampel dependen dengan derajat kemaknaan 0,005. 
Hasil Analisa bivariat, dapat terlihat dari table berikut ini:

Tabel 1.2

\begin{tabular}{|c|c|c|c|c|c|}
\hline Pengukuran & Waktu & Mean & Median & SD & Min-Max \\
\hline \multirow[t]{11}{*}{ RR } & Sebelum & & & & \\
\hline & Hari 1 & 35,22 & 36 & 1,26 & $20-36$ \\
\hline & Hari 2 & 36,17 & 37 & 1,31 & $20-37$ \\
\hline & Hari 3 & 36 & 36,67 & 1,27 & $19,67-37$ \\
\hline & Rerata & 36,13 & 36,90 & 1,24 & 20-37 \\
\hline & Sesudah & & & & \multirow{6}{*}{$\begin{array}{r}21-25,33 \\
20,67-25 \\
20,67-25,33 \\
20,80-25,10\end{array}$} \\
\hline & Hari 1 & 25,09 & 23,17 & 1,29 & \\
\hline & Hari 2 & 25,81 & 22,83 & 1,06 & \\
\hline & Hari 3 & 25,55 & 23,67 & 1,33 & \\
\hline & \multirow[t]{2}{*}{ Rerata } & & & & \\
\hline & & 25,15 & 23,10 & 1,08 & \\
\hline \multirow[t]{10}{*}{ SPO2 } & Sebelum & & & & \\
\hline & Hari 1 & 94,59 & 94,67 & 0,82 & $93-96$ \\
\hline & Hari 2 & 94,68 & 95 & 0,79 & $93-96$ \\
\hline & Hari 3 & 94,67 & 95 & 0,78 & $93-96$ \\
\hline & Rerata & 94,65 & 94,90 & 0,78 & 9396 \\
\hline & \multicolumn{5}{|l|}{ Sesudah } \\
\hline & Hari 1 & 96,17 & 96 & 0,78 & $95-97,33$ \\
\hline & Hari 2 & 96,20 & 96,12 & 0,68 & $95-97$ \\
\hline & Hari 3 & 96,15 & 96,15 & 0,76 & 95-97 \\
\hline & Rerata & 96,17 & 96,10 & 0,73 & $95-97,10$ \\
\hline
\end{tabular}

Berdasarkan tabel 1.2 di atas, rerata hasil pengukuran Respiratory rate sebelum intervensi posisi Prone : $36,13 \mathrm{x} / \mathrm{mnt}$ dan setelah intervensi:

\section{PEMBAHASAN}

\section{Gambaran Karakteristik Responden}

Berdasarkan hasil analisis usia gestasi dengan status oksigenasi $\mathrm{P}$ value $<\alpha(0,05)$ artinya ada hubungan usia gestasi dengan RR dan SPO2, dengan kekuatan hubungan kategori sedang (0.400-0.599). Hal ini sejalan dengan teori yang diungkapkan bahwa usia gestasi kurang dari 28 minggu biasanya diikuti dengan immaturitas parenkim paru, dinding dada dan endothelium kapiler yang menyebabkan kolaps paru pada akhir ekspirasi (Marcdante, 2014).
25,15 x/mnt. Hasil rerata pengukuran SPO2 sebelum intervensi posisi Prone : $94,65 \%$ dan setelah intervensi: $96,17 \%$.

Hal ini terjadi disebabkan oleh defisiensi surfaktan pada immaturitas. Surfaktan adalah suatu kompleks lipoprotein, untuk mencegah kolapsnya alveolus. Apabila surfaktan tersebut tidak adekuat, maka akan menyebabkan kolapsnya alveoli dan hipoksia. Kondisi ini akan meneyebabkan terjadinya kontriksi vaskuler dan penurunan perfusi pulmonary, yang akhirnya mengakibatkan sindrom gawat napas atau bahkan bisa berlanjut ke gagal napas progresif (Marni, 2014).

Berdasarkan hasil analisis $\mathrm{Hb}$ dengan status oksigenasi $\mathrm{P}$ value $<\alpha$ 
$(0,05)$ artinya ada hubungan $\mathrm{Hb}$ dengan RR dan SPO2, dengan kekuatan hubungan kategori sedang (0.400-0.599). Hal ini senada pernyataan sebuah penelitian serupa bahwa $\mathrm{Hb}$ adalah bagian utama dari sel darah merah yang berfungsi mengikat oksigen HBO (Marcdante, 2014).

Pada kasus dimana kondisi sel-sel darah merah (eritrosit) dan/atau $\mathrm{Hb}$ dalam darah berada dibawah nilai normal maka akan mempengaruhi saturasi oksigen (SPO2). SPO2 yaitu presentasi hemoglobin yang berikatan dengan oksigen di dalam arteri. Saturasi oksigen normal adalah 95\% - 100\% (S Ozyurex, 2012).

Faktor yang mempengaruhi SPO2 salah satunya adalah Hb. Jika $\mathrm{Hb}$ tersaturasi penuh dengan $\mathrm{O2}$ walaupun nilai $\mathrm{Hb}$ rendah maka SPO2 akan menunjukkan nilai normalnya. Misalnya pada klien dengan anemia memungkinkan nilai $\mathrm{SpO} 2$ dalam batas normal. Namun jika nilai $\mathrm{Hb}$ rendah, maka kemampuan tubuh untuk mengikat oksigen juga menurun, ikatan $\mathrm{HBO}$ juga menurun dan hal ini akan membuat nilai SPO2 menjadi menurun (RK Albert, 2000). Berdasarkan karakteristik suhu tubuh bayi dengan RDS di ruang NICU RSUD Gunung Jati Cirebon pada kelompok intervensi posisi prone rata-rata $37.16^{\circ} \mathrm{C}$, Hasil analisis usia suhu dengan status oksigenasi $P$ value $>\alpha(0,05)$ maka Ho diterima artinya tidak ada hubungan suhu dengan RR dan SPO2. Pernyataan sebuah penelitian yang serupa menyatakan bahwa tidak terdapat hubungan yang signifikan antara peningkatan suhu dengan oksigen dalam darah (Anggrek, 2008).

\section{Gambaran untervensi posisi prone} Hasil penelitian diketahui bahwa pada kelompok intervensi posisi Prone, pengukuran RR sebelum intervensi posisi prone rata-rata 21,13, dan setelah intervensi posisi prone: 23,15. Ada perbedaaan RR sebelum dan sesudah intervensi posisi prone dengan kenaikan ratarata RR sebesar 2,03 (9,61\%).

Pengukuran SPO2 sebelum intervensi posisi prone rata-rata 94,65 dan setelah intervensi posisi prone 96,17. Ada perbedaaan SPO2 sebelum dan sesudah intervensi posisi prone dengan kenaikan ratarata SPO2 sebesar 1.52 (1.61\%).

Posisi prone mempunyai banyak keuntungan karena posisi ini dapat mengurangi pengeluaran energi, meningkatkan kemampuan bernafas dan meningkatkan kemampuan saturasi oksigen (M.R Alligood, 2010).

\section{KESIMPULAN}

Kesimpulan dari penelitian ini adalah terdapat peningkatan respiratory rate dan saturasi oksigen setelah dilakukan intervensi posisi prone.

Hal ini sesuai dengan salah satu penelitian serupa yang menyatakan bahwa posisi prone sangat efektif dilakukan pada bayi (YR Bhat, 2006).

Didukung oleh hasil penelitian senada, yang menyatakan bahwa pada bayi dengan gawat napas (RSD) dengan pemberian posisi prone dapat membantu untuk mengurangi sesak pada bayi ( L Gattinoni et all, 2013).

Demikian pula penelitian lain terkait posisi prone pada severe acute respiratory distress syndrome, menyatakan bahwa ada perubahan status oksigenasi yaitu peningkatan respiratory rate dan oksigen saturasi setelah diberikan posisi prone (C Guerin et all, 2013). 


\section{DAFTAR PUSTAKA}

Albert RK, Hubmayr RD. (2000). The prone position compression of the lungs by the heart. Am J Respir Crir Care Med: 161:1660-5.

Alligood, M.R., \& Tomey, A.M. (2010). Nursing theories and their work, $7^{\text {th }}$ edition. St. Louis: Mosby.

Anggrek. K. Runtunuwu. A.L. Wahani. A. Margaretha. L. (2008). Faktor Resiko Kejadian Distress Pernapasan pada Anak dengan Pneumonia. Vol. 9. No. 6: 391-397.

Anggrek. K. Runtunuwu. A.L. Wahani. A. Margaretha. L. (2008). Faktor Resiko Kejadian Distress Pernapasan pada Anak dengan Pneumonia. Sari Pediatri. Vol. 9. No. 6: 391-397.

Bhat YR, Hannam S, et al. (2006). Effect of prone and supine position on sleep, apneas, and asausalnin pratem infants. Paediatrics;118:101.

Gattinoni L, Taccone P, Carlesso E, et al. (2013). Prone position in acute respiratory distress syndrome: Rationale, indications, and limits; Am J Respir Crit Care Med:Vol 188: Iss 11: pp 1286-1293.

Guerin C, Reigner J, Richard JC, et al. (2013). Prone positioning in severe acute respiratory distress syndrome. $\mathrm{N}$ Eng $\mathrm{J}$ Med;368:2159-68.
Kusumaningrum, Arie (2010) Faktor yang mempengaruhi nilai SpO2 pasca pronasi pada bayi yang memakai ventilator. Jurnal Kedokteran dan Kesehatan, 42 (02). pp. 28872892. ISSN 0-853-1773.

Marcdante JK, Kliegman MR, et al (2014). Nelson: Ilmu Kesehatan Anak Esensial. Edisi 6. Saunders Elsevier Inc: Singapore.

Marni (2014). Asuhan Keperawatan Pada Anak Sakit Dengan Gangguan Pernapasan. Jilid I: Gosyen Publishing: Yogyakarta.

Ozyurex. S, A. Genc, Koca (2012) dalam penelitiannya yang berjudul Respiratory hemodinamic responses to mobilization of critically ill patient. Cardiopulmonal Physical Therapy Journal, Volume 23, Issue 1, March 2012.

RSUD Gunung Jati Cirebon. (2018). Profil RSUD Gunung Jati Cirebon.

Wong Donna L, Hockenberry M, et al. (2009). Buku ajar keperawatan pediatric. Vol. 2, Ed. 6. EGC: Jakarta.

Wong Donna L, Hockenberry $M$, et al. (2009). Buku ajar keperawatan pediatric. Vol. 1, Ed. 6. EGC: Jakarta.

World Health Organization. (2011). World Health Statistics. Available at http://www. who.int/whosis /whostat/EN_WHS2011_Full. pdf. 